\title{
Numerical Simulation Study on the Effects of Diatomic Gas Addition on Soot and Its Precursors in Acetylene Premixed Flame
}

\author{
Hassan Osaf Ali', Muhammad Hassaan Athar², Talha Nadeem Hassan³, Faheem-ul-Hasnain ${ }^{4}$, \\ Muhammad Azeem Ghouri ${ }^{5}$ \\ ${ }^{1} \mathrm{Xi}$ 'an Jiaotong University \\ Xi'an, China \\ hassan0787@stu.xjtu.edu.cn; hassaanathar2@stu.xjtu.edu.cn \\ ${ }^{2} \mathrm{Xi}$ 'an Jiaotong University \\ Xi'an, China
}

\begin{abstract}
In order to study the PAHs and soot volume fraction, CHEMKIN software was used for the analysis of $\mathrm{H}_{2}, \mathrm{CO}_{\text {and }} \mathrm{N}_{2}$ effects on the PAHs and soot formation in a premixed laminar $\mathrm{C}_{2} \mathrm{H}_{2}$ flame numerically. To have good understanding on effects of additives on PAH formation and intermediate species like $\mathrm{OH}, \mathrm{H}_{2}$ and $\mathrm{C}_{2} \mathrm{H}_{2}, \mathrm{C}_{3} \mathrm{H}_{3}, \mathrm{C}_{4} \mathrm{H}_{4}, \mathrm{C}_{5} \mathrm{H}_{5}$ and soot volume fraction, some simulations were performed under different addition ratios $(0 \%, 20 \%$ and $40 \%)$ of $\mathrm{H}_{2}, \mathrm{CO}$ and $\mathrm{N}_{2}$. The $\mathrm{ABF}$ mechanism which includes $\mathrm{C}_{1}$ and $\mathrm{C}_{2}$ chemistry, PAH growth was used to understand the particle inception and mole fractions of intermediate species. Prior to performing simulation, the performance of model prediction for soot, $\mathrm{PAH}$ and mole fraction of intermediate products was validated and calculations were performed and compared with the experimental results. Hydrogen showed strong chemical effect when it is added into the unburned mixture. The mole fractions of important soot antecedent species such $\mathrm{C}_{2} \mathrm{H}_{2}$ and $\mathrm{PAH}$ were inhibited significantly as compared to the cases of $\mathrm{CO} / \mathrm{N}_{2}$ addition. However, the aromatic radical is limited by the excess of $\mathrm{H}_{2}$, thus causing the lower production rate of large PAHs. In addition, results showed that hydrogen, carbon Monoxide and nitrogen additions lead to the reduction of temperature. To study the effects of additions on soot generation, $\mathrm{N}_{2} / \mathrm{CO} / \mathrm{H}_{2}$ were added to $\mathrm{C}_{2} \mathrm{H}_{2} /$ air flame from $0 \%$ to $40 \%$. The results showed that $\mathrm{N}_{2} / \mathrm{CO} / \mathrm{H}_{2}$ reduced the soot volume fraction.
\end{abstract}

Keywords: $\mathrm{H}_{2} / \mathrm{CO} / \mathrm{N}_{2}$ addition; Polycyclic Aromatic Hydrocarbon; Premixed Flame; Soot;

\section{Introduction}

At present, the world's vitality request is relying upon the ignition of non-renewable energy sources, while the burning of petroleum derivative produces $\mathrm{NOx}$ and $\mathrm{CO}_{2}$ pollutants and hydrocarbons including polycyclic aromatic hydrocarbons (PAHs) compounds and different contamination unavoidably [1], [2]. Polycyclic aromatics hydrocarbons are organic compounds having carbon and hydrogen and are the precursors of soot. Soot is one of the most important emissions of fossil fuels after combustion. Although the whole process of PAH and soot formation has been known but the in-depth process of $\mathrm{PAH}$ and soot formation and oxidation is required to be further understood. The detailed mechanism is the theoretical basis to guide the reduction of PAH and soot generation, so the study of PAH and soot generation within the flame is still a hot topic in today's society. Guo et al. [3] examined the effects on soot production in $\mathrm{C}_{2} \mathrm{H}_{4} /$ air diffusion flames by adding $\mathrm{CO}$ and chemically constraining impact was qualified to the reduce the amount hydrogen atoms in the surface growth area and higher absorption of molecular hydrogen in the lower flame region. Gulder et al. [4] in his work presented the effects of $\mathrm{H}_{2}$ in the ethylene, propane and butane jet diffusion flames and detected some uncertainties in visible flame length and along the diameter of flame. It was concluded that when $\mathrm{H}_{2}$ was added in reasonable amount, a lesser impact on temperature field was detected. Choudhary and Gollahalli [5] investigated the structure of flame and attributes of diffusion flames of hydrogenhydrocarbon fuel in co-flowing air stream. In their work, it was seen that the length of flame was increased as propane quantity was increased in the mixture of hydrogen-hydrocarbon. Henríquez et al. [6] experimentally analysed the impacts of oxygen index against the soot production in co flow laminar, propane diffusion flames. In his study, he concluded that as the oxygen index increases with soot growth along with oxidation rate, the maximum soot volume fraction showed incremental rate with overall peak soot volume. Considerable amount of work exists in literatures focusing the influence adding hydrogen on soot formation. Particularly, premixed benzene and kerosene flames, caused a low increase in yellow luminosity by the addition of hydrogen[7]. 
The first objective of this work was to validate the model accuracy. Simulations were done and compared with the experimental data. After the model validation, the second objective of this work was to study or analyse the effects of $\mathrm{H}_{2}$, $\mathrm{CO}$ and $\mathrm{N}_{2}$ additives in $\mathrm{C}_{2} \mathrm{H}_{2}$ /air flame and also analyse their effects on major species, aromatic formation and soot volume fraction. The last but not least objective was to use the model to numerically evaluate the formation of PAH and soot in Laminar Premixed Burner Flame by using CHEMKIN software to advance the understanding of PAH and soot formation mechanism.

\section{Numerical Model and Kinetic Model for Soot}

Simulations were made in two steps for the evolution of particle. In first step, the concentration of the gaseous species and evolution of moments of soot particle size distribution was made [8]. Used a detailed simulation of the size of soot distribution chemical reaction mechanism in the gas phase [9] and soot formation [10]. Secondary by using Monte Carlo stochastic approach, the soot size distribution can be calculated. To find gaseous species use PREMIX flame code which is a CHEMKIN package subroutine [11]. The procedures of soot particles construction were depicted based on the detailed kinetic soot model and the method of moments created by Frenklach and co-workers [9].

Governing Equations

Equation for the one dimensional propagation of flame can represented as following [10]:

Continuity Equation:

Energy Equation:

$$
\mathrm{M}=\rho \mathrm{uA}
$$

$$
\dot{\mathrm{M}} \frac{d T}{d x}-\frac{1}{c_{p}} \frac{d}{d x} \lambda \mathrm{A} \frac{d T}{d x}+\frac{\mathrm{A}}{c_{p}} \sum_{\mathrm{K}=1}^{\mathrm{K}} \rho \mathrm{Y}_{k} \mathrm{~V}_{k} c_{p k} \frac{d T}{d x}+\frac{\mathrm{A}}{c_{p}} \sum_{\mathrm{K}=1}^{\mathrm{K}} \dot{w}_{k} h_{k} \mathrm{~W}_{k}=0
$$

Species Equation:

$$
\dot{\mathrm{M}} \frac{d T}{d x}-\frac{1}{c_{p}} \frac{d}{d x} \lambda \mathrm{A} \frac{d T}{d x}+\frac{\mathrm{A}}{c_{p}} \sum_{\mathrm{K}=1}^{\mathrm{K}} \rho \mathrm{Y}_{k} \mathrm{~V}_{k} c_{p k} \frac{d T}{d x}+\frac{\mathrm{A}}{c_{p}} \sum_{\mathrm{K}=1}^{\mathrm{K}} \dot{w}_{k} h_{k} \mathrm{~W}_{k}=0
$$

Where, $(\mathrm{k}=1, \ldots \ldots, \mathrm{K}), \mathrm{x}$ represents spatial coordinate, $\mathrm{M}$ represents mass flow rate, $\mathrm{T}$ is for temperature, $\mathrm{Y}_{k}$ is the mass fraction of kth species, $\mathrm{p}$ is pressure, $\rho$ is mass density, $\mathrm{u}$ is the velocity of the fluid mixture, $\mathrm{W}_{k}$ is the molecular weight of kth species, $\lambda$ is the mixture thermal conductivity, $c_{p}$ is the constant-pressure, $\dot{w}_{k}$ is the molar rate of production by the chemical reaction of kth species per unit volume, $h_{k}$ is the specific enthalpy of kth species, $V_{k}$ is the diffusion velocity of kth species, $A$ is the cross-section area of stream tube.

For the modelling of soot production, a model known as discrete section is used. And the development includes the reaction of gaseous species upto $\mathrm{PAH}$, from the gas to particle formation process combined to elementary mechanism. Particles dynamical model incorporates nucleation, coagulation, and condensation of PAHs onto the surface of soot particles and surface development i.e., the introduction of acetylene to radical sites on surface, and oxidation process caused by hydroxyl radical and molecular oxygen.

Soot inception

The inception of soot is described by coagulation of PAH molecules. Production process of primary soot particles are being represented as dimerization of two molecules of pyrene.

$$
\begin{gathered}
\mathrm{PAH}_{\mathrm{i}}+\mathrm{PAH}_{\mathrm{j}} \rightarrow \text { Soot }_{\mathrm{i}+\mathrm{j}} \\
R(t)=\frac{1}{2} \beta N_{P A H S} N_{P A H S}
\end{gathered}
$$

Where, $R(t)$ is the nucleation rate, $\beta$ is the collision kernel, $N_{P A H S}$ is the molar concentration of PAHs.

Soot coagulation

Smoluchowski's equation is describing the soot coagulation process which is follow as: 


$$
\mathrm{G}(i)=\frac{1}{2} \sum_{j=1}^{i-1} \beta_{j, i-j} N_{j} N_{i-j}-\sum_{j=1}^{n_{\max }} \beta_{i, j} N_{i} N_{j}
$$

Where, $\beta_{i, j}$ is the coagulation frequency.

Soot surface reaction

The condensation of pyrene and acetylene addition through HACA mechanism includes the surface growth reaction of soot.

$$
\begin{gathered}
\text { Soot }_{i}+\mathrm{A}_{4} \rightarrow \text { Soot }_{\mathrm{i}+16} \\
\text { Soot }_{\mathrm{i}}+\mathrm{C}_{2} \mathrm{H}_{2} \rightarrow \text { Soot }_{\mathrm{i}+2}
\end{gathered}
$$

Molecular oxygen and $\mathrm{OH}$ radicals in the oxidation process of soot particles, are considered to react with two gaseous.

$$
\begin{aligned}
& \text { Soot }_{\mathrm{i}}+\mathrm{OH} \rightarrow \text { Soot }_{\mathrm{i}-1} \\
& \text { Soot }_{\mathrm{i}}+\mathrm{O}_{2} \rightarrow \text { Soot }_{\mathrm{i}-2}
\end{aligned}
$$

\subsection{Model Validation}

For the sake to validate present work, calculations were made and comparison was done to the experimental data of previous studies which is obtained in Figure 1, Figure 2 [9], Figure 3 [12] and Figure 4 [12]. As Figure 1 illustrate a typical premixed laminar flame structure, which consists of unburned mixture region, the transport region, the reaction region and burned mixture region.

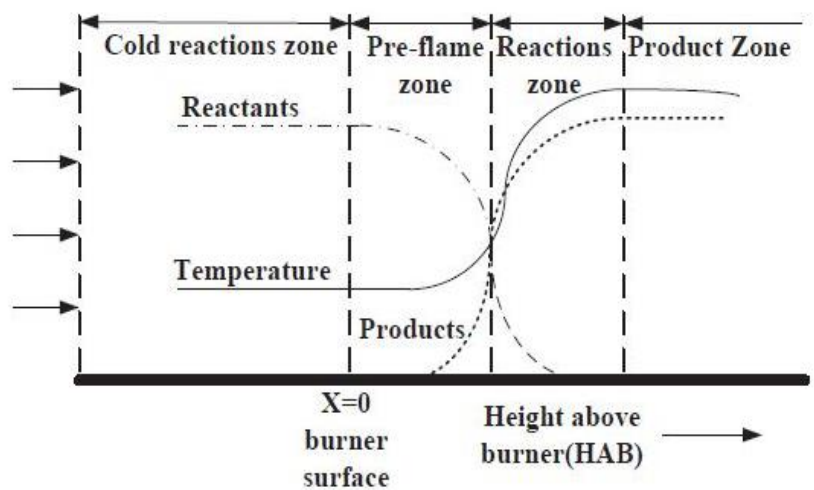

Fig. 1: Schematic of one-dimensional premixed flame configuration.

Figure 2 demonstrates the simulated mole fraction of different species and temperature with the experimental data of previous studies [9] by ABF mechanism. It is clearly seen that there is good agreement between experimental data of mole fractions of major products and temperature with respect to HAB and calculated data. In all Figures the symbols are showing the experimental data while lines are representing the simulated data.

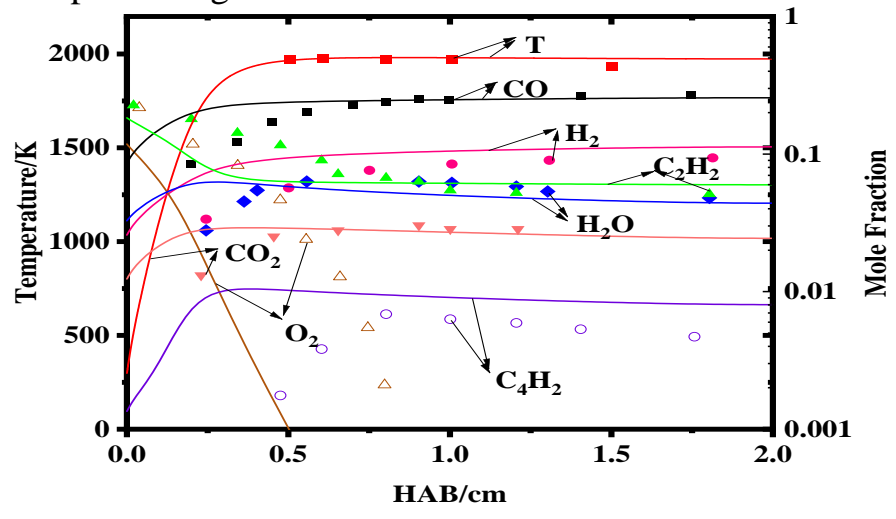


Fig. 2: Comparison of calculated and experimental data of mole fractions profiles for major products in pure $\mathrm{C} 2 \mathrm{H} 2 /$ air flames [9] by ABF mechanism.

Figure 3 demonstrates the simulated mole fraction of benzene and naphthalene with the experimental data of studies [12]. It is clearly seen that the calculated date agreed well with experimental data of mole fractions of benzene naphthalene with respect to $\mathrm{HAB}$ by using $\mathrm{ABF}$ mechanism.

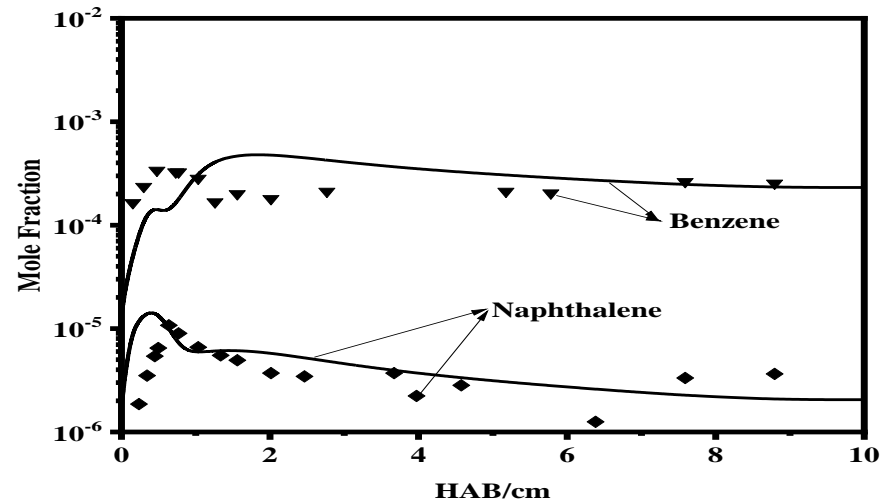

Fig. 3: Comparison of calculated and experimental data [12] of $\mathrm{PAH}$ in pure $\mathrm{C}_{2} \mathrm{H}_{2} /$ air flames by $\mathrm{ABF}$ mechanism.

Figure 4 demonstrates the calculation of soot volume fraction and experimental data of previous studies [12]. It can be clearly understood that the calculated date showed excellent agreement with the experimental data of soot volume fraction with respect to $\mathrm{HAB}$.

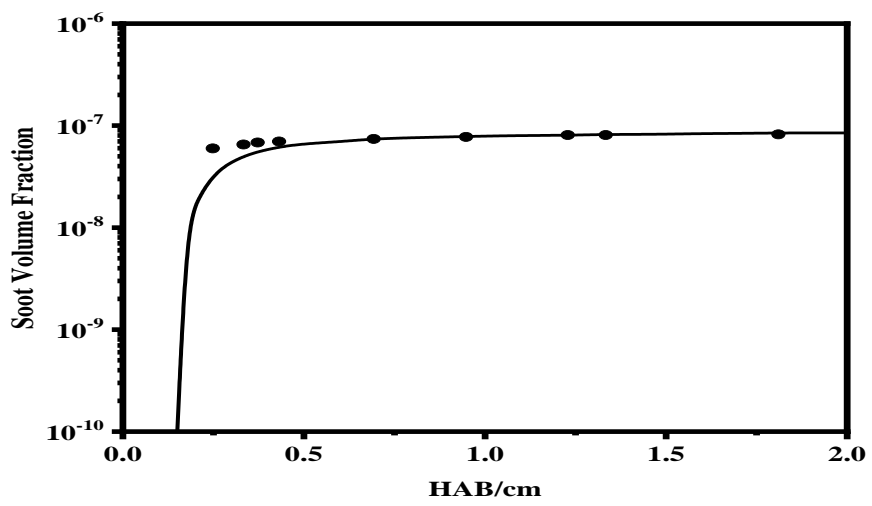

Fig. 4: Comparison of calculated and experimental data [12] of soot volume fraction in pure $\mathrm{C}_{2} \mathrm{H}_{2} /$ air flames.

\subsection{Boundary Conditions}

The following tables 1 and 2 represent the calculation conditions for the simulation of $\mathrm{C}_{2} \mathrm{H}_{2} /$ air Flame.

Table 1: Calculation conditions for $\mathrm{C} 2 \mathrm{H} 2 /$ air Flame.

\begin{tabular}{|l|l|}
\hline Quantity & Range \\
\hline Pressure & 0.12 bar \\
\hline $\begin{array}{l}\text { Initial } \\
\text { Temperature }\end{array}$ & $298 \mathrm{~K}$ \\
\hline $\begin{array}{l}\text { Equivalence } \\
\text { Ratio }\end{array}$ & 2.75 \\
\hline
\end{tabular}


Table 2: Calculation conditions for $\mathrm{C} 2 \mathrm{H} 2 /$ air Flame.

\begin{tabular}{|l|l|l|l|}
\hline $\begin{array}{l}\mathrm{H}_{2}, \mathrm{CO}, \mathrm{N}_{2} \\
\text { (Volume) }\end{array}$ & $0 \%$ & $20 \%$ & $30 \%$ \\
\hline $\mathrm{C}_{2} \mathrm{H}_{2}$ & 0.188 & 0.176 & 0.165 \\
\hline $\mathrm{O}_{2}$ & 0.171 & 0.166 & 0.162 \\
\hline $\mathrm{N}_{2}$ & 0.641 & 0.623 & 0.607 \\
\hline $\mathrm{H}_{2}$ & 0 & 0.035 & 0.066 \\
\hline $\mathrm{CO}$ & 0 & 0.035 & 0.066 \\
\hline $\mathrm{N}_{2}$ & 0 & 0.035 & 0.066 \\
\hline
\end{tabular}

\section{Results and Discussion}

\section{PAH with the addition of $\mathrm{H}_{2}, \mathrm{CO}, \mathrm{N}_{2}$ :}

The production of Benzene (A1) by the decomposition of fuel is measured as a vital intermediate to develop PAH. Since, the production of Benzene changes the rate-limiting point in the reaction order to enhance PAHs. Figure 5(a) A1 has been as a function of the HAB. For the $\mathrm{C}_{2} \mathrm{H}_{2} / \mathrm{H}_{2} /$ air flames, the addition of hydrogen suppresses the formation of A1 near the burner surface. Due to the addition of hydrogen, mole fraction of A1, became higher and increases as the HAB increases. It is increased because the reverse rate of the $\mathrm{H}$ abstraction reaction due to abundance of $\mathrm{H}_{2}$. Therefore, converting more phenyls (A1-) into A1 (benzene). Similarly, the increased $\mathrm{H}_{2}$ concentration can control further growth of PAH. Furthermore, Figure 5(b) elucidates the mole fraction of A2 which increased with a slightly fluctuated curves. After achieving its maximum value when the $\mathrm{H}_{2}$ addition was $0 \%$ and $20 \%$, A2 gradually decreased because the increased $\mathrm{H}_{2}$ concentration can control further growth of PAH. On the other hand, $40 \% \mathrm{H}_{2}$ addition was totally different from $0 \%$ and $20 \%$ hydrogen addition because it depicts, more $\mathrm{H}_{2}$ can control PAH growth near the maximum peak. Additionally, Figure 5(c) illustrates the mole fraction of A3. The mole fraction of $20 \% \mathrm{H} 2$ addition was higher than $0 \% \mathrm{H}_{2}$. Contrary to this when $\mathrm{H}_{2}$ was $40 \%$ it showed fluctuation from very beginning till its maximum value. Overall Figure 5(c) shows the mole fraction of A3 increased till a specific value, after that it will decrease even with addition of $\mathrm{H}_{2}$. Finally, Figure 5(d) shows the mole fraction of A4 decreases by adding the hydrogen. More hydrogen additive is having stronger chemical effect on A4 formation. That's why in $\mathrm{C}_{2} \mathrm{H}_{2} / \mathrm{H}_{2} / \mathrm{air}$ flame, the mole fraction of $\mathrm{A} 4$ was found lower. The $\mathrm{H}$-abstraction $\mathrm{C}_{2} \mathrm{H}_{2}$-addition (HACA) mechanism for PAH growth can explain this actions. According to HACA mechanism the first aromatic ring of benzene (A1) is important.
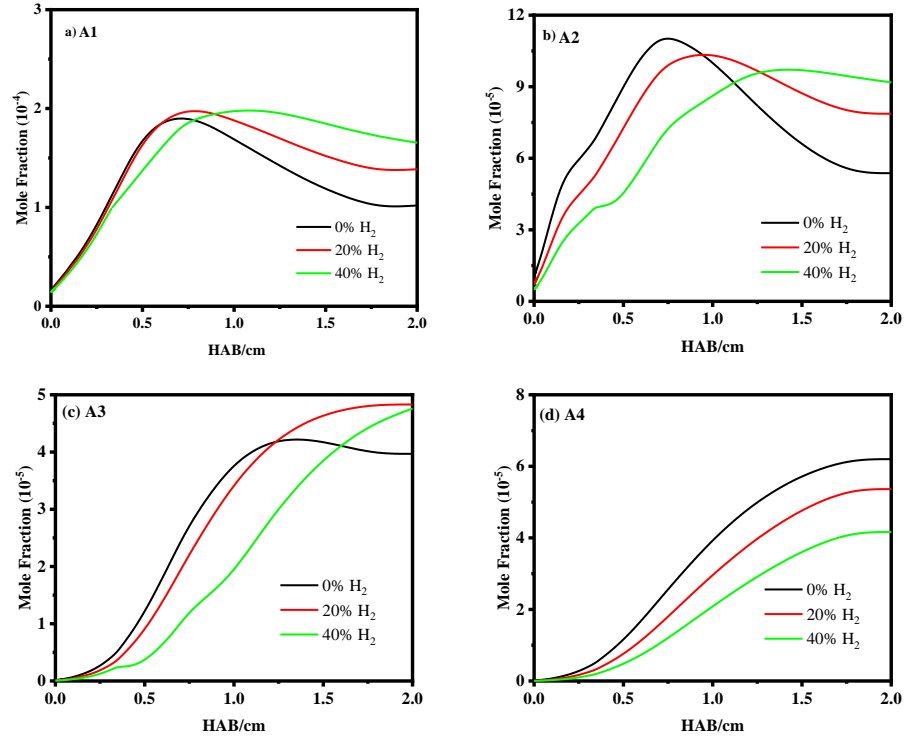

Fig. 5: Mole Fraction (a)A1, (b)A2, (c)A3, (d)A4 with HAB. 
As due diluent effect of $\mathrm{CO}$ which cause lower in $\mathrm{C}_{2} \mathrm{H}_{2}$ concentration results lower the PAHs production rate (which explained in chemical effects) which cause increases in A1, A2 and A3 with increasing HAB but the mole fraction of decreased by the addition of $\mathrm{CO}$ due to its diluent nature as presented in Figure 6(a)(b)(c)(d). Firstly, it can be seen that variation tendency of $\mathrm{A} 1$ and $\mathrm{A} 2$ are all increased firstly and decreased. The mole fraction of A1 and A2 decreased in a way from 0.5 to $2 \mathrm{~cm}$ of $\mathrm{HAB}$ by the addition of $\mathrm{CO}$ as shown in Figure 6(a) and Figure 6(b). As it is represented in figure 6(c)\&(d), the change trend of A3 and A4 are all increased and until to a flat state. The reduction of A4 is happened because of dilution. So, the increased $\mathrm{CO}$ concentration can control further growth of PAH due to dilution effect as shown in Figure 6.
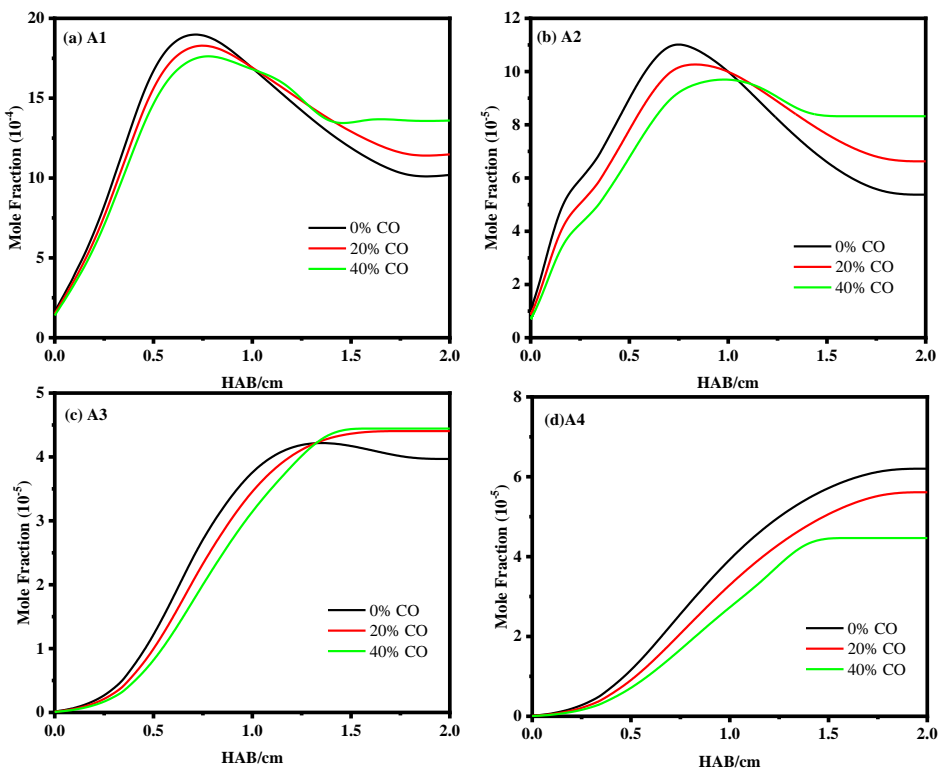

Fig. 6: Mole Fraction (a)A1, (b)A2, (c)A3, (d)A4 with HAB.

As $\mathrm{N}_{2}$ is affecting on $\mathrm{C}_{2} \mathrm{H}_{2}$ due to diluent in nature, thus the lower in $\mathrm{C}_{2} \mathrm{H}_{2}$ concentration results lower the PAHs production rate (which is explained in chemical effects) which cause decrease in A1, A2 and A4 with increasing HAB but the mole fraction of $A 3$ increased by the addition of $N_{2}$ as mentioned in Figure $7(a)(b)(c)(d)$, represents the mole fraction of A1, A2, A3 and A4 as a function of HAB. So, the increased $\mathrm{N}_{2}$ concentration can control further growth of PAH due to dilution effect as shown in Figure 7. 

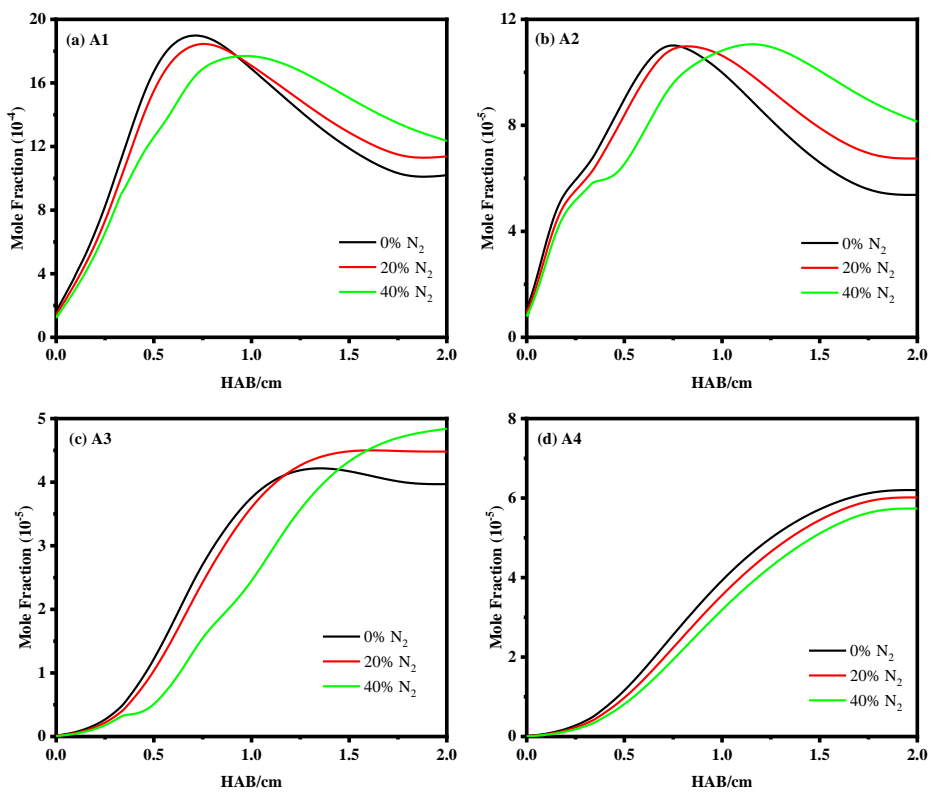

Fig. 7: Mole Fraction (a)A1, (b)A2, (c)A3, (d)A4 with HAB.

\section{Thermal Effect:}

The additions of $\mathrm{H}_{2}, \mathrm{CO}, \mathrm{N}_{2}$ into $\mathrm{C}_{2} \mathrm{H}_{2}$ /air laminar premixed flame affects thermally and their additions in $\mathrm{C}_{2} \mathrm{H}_{2} /$ air flame decrease the temperature. From figure 8 , it is worth mentioning flame temperature as function of HAB. When there was $0 \%$ addition of $\mathrm{H}_{2}, \mathrm{CO}$ and $\mathrm{N}_{2}$ in $\mathrm{C}_{2} \mathrm{H}_{2}$ /air, the maximum temperature was $1742 \mathrm{~K}$. By increasing the concentration of $\mathrm{H}_{2}, \mathrm{CO}$ and $\mathrm{N}_{2}$ in $\mathrm{C}_{2} \mathrm{H}_{2}$ /air, the temperature decreases and for $20 \%$ concentration of $\mathrm{H}_{2}, \mathrm{CO}$ and $\mathrm{N}_{2}$ it reduced to $1710 \mathrm{~K}, 1719 \mathrm{~K}$ and $1725 \mathrm{~K}$, respectively. Similarly, for $40 \%$ concentration of $\mathrm{H}_{2}, \mathrm{CO}$ and $\mathrm{N}_{2}$, the temperature reduced to $1682 \mathrm{~K}, 1691 \mathrm{~K}$ and $1710 \mathrm{~K}$ respectively. This showed that these all additives have thermal effect. $\mathrm{H}_{2}$ had more significant effect on temperature than $\mathrm{CO}$ and $\mathrm{N}_{2}$ did.

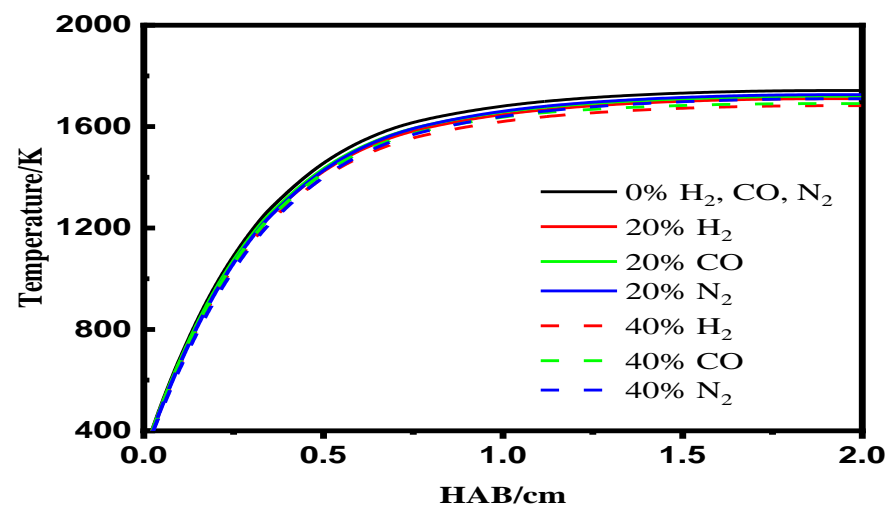

Fig. 8: Mole Fraction (a)A1, (b)A2, (c)A3, (d)A4 with HAB.

\section{Chemical Effect on major species:}

The effect of additives due to the chemical has been discussed. In order to know how the chemical reactions, influence the PAH, some important gas phase species were simulated.

Figure 9 (a) representing the mole fractions of $\mathrm{OH}$. Reduction in mole fraction of hydroxyl is due to chemical effect with $\mathrm{H}_{2}$ additions. By adding $\mathrm{H}_{2}$ the rate of forward reaction is accelerated and it consumes more $\mathrm{OH}$ radical which causes 
lower the $\mathrm{OH}$ radical quantity. Same time, more $\mathrm{H}$ atoms are formed. Reaching their peak values, mole concentrations of hydroxyl reduces quickly, with $\mathrm{HAB}$. The following reaction might take place:

$$
\mathrm{H}_{2}+\mathrm{OH} \rightarrow \mathrm{H}_{2} \mathrm{O}+\mathrm{H}
$$

When different percentage of $\mathrm{H}_{2}$ is added in mole fraction of $\mathrm{H}_{2}$, the concentration of $\mathrm{H}_{2}$ obviously increased. It is clearly seen in Figure 9 (b) that as increased the percentage of $\mathrm{H}_{2}$, quantity of $\mathrm{H}_{2}$ also increased due to chemical effect. The following reaction might take place:

$$
\mathrm{H}_{2}+\mathrm{H}_{2} \rightarrow 2 \mathrm{H}_{2}
$$

The $\mathrm{C}_{2} \mathrm{H}_{2}$ /air pyrolysis is through the following reactions:

$$
\begin{gathered}
\mathrm{C}_{2} \mathrm{H}_{2}+\mathrm{O} \rightarrow \mathrm{CO}+\mathrm{CH}_{2} \\
\mathrm{C}_{2} \mathrm{H}_{2}+\mathrm{O} \rightarrow \mathrm{H}+\mathrm{HCCO} \\
\mathrm{C}_{2} \mathrm{H}_{2}+\mathrm{H} \rightarrow \mathrm{C}_{2} \mathrm{H}_{3}
\end{gathered}
$$

As the concentration of $\mathrm{H}_{2}$ increases with the mole fraction to the $\mathrm{C}_{2} \mathrm{H}_{2}$ /air flame, from equation 14 the reaction is inhibited while the reaction of 15 is promoted. Considering the competition between the two reactions, the concentration of $\mathrm{C}_{2} \mathrm{H}_{2}$ decreases as shown in Figure 9 (c). Figure 9 (d) describes mole fraction of $\mathrm{C}_{3} \mathrm{H}_{3}$ with increased HAB. On the whole, the concentration of $\mathrm{C}_{3} \mathrm{H}_{3}$ first increased and then decreased to a flat state with $\mathrm{HAB}$. The mole fraction is maximum at $0 \%$ $\mathrm{H}_{2}$ addition and it continuously decreased with the addition of $\mathrm{H}_{2}$ due to chemical effect. As Figure 9 (d) explains, when the $\mathrm{H}_{2}$ was $20 \%$ the mole fraction was less than $0 \%$ and when $\mathrm{H}_{2}$ was $40 \%$, it showed an obvious different behaviour with fluctuated increase. In Figure 9 (e) the relationship between mole fraction of $\mathrm{C}_{4} \mathrm{H}_{4}$ (with $0 \%, 20 \%$ and $40 \% \mathrm{H}_{2}$ additive) and $\mathrm{HAB}$ has shown. It can be seen that the concentration of $\mathrm{C}_{4} \mathrm{H}_{4}$ presents a non-monotonic change, and its change trend increases first and then decreases with the increase of $\mathrm{HAB}$. When $0 \% \mathrm{H}_{2}$ additive is used, the peak value of mole fraction is the maximum whereas the peak value is smaller for $20 \%$ and $40 \% \mathrm{H}_{2}$ additive conditions respectively. It is interesting to notice that for $40 \% \mathrm{H}_{2}$ additive, the decline after the peak value is slower than the other two cases, and the value is greater than in the other two cases. Figure 9 (f) depicts the relationship between mole fraction of $\mathrm{C}_{5} \mathrm{H}_{5}$ (with $0 \%, 20 \%$ and $40 \% \mathrm{H}_{2}$ additive) and $\mathrm{HAB}$. As can be seen from the figure, the concentration of $\mathrm{C}_{5} \mathrm{H}_{5}$ gradually increases to a flat state with the increase of $\mathrm{HAB}$. The graph shows when there was no $\mathrm{H}_{2}$ additives the mole fraction of $\mathrm{C}_{5} \mathrm{H}_{5}$ is minimum, whereas for $20 \%$ $\mathrm{H}_{2}$ additive the value of mole fraction $\mathrm{C}_{5} \mathrm{H}_{5}$ is maximum and for $40 \% \mathrm{H}_{2}$ additive it decreased more significantly than $20 \%$ $\mathrm{H}_{2}$ additive case does. 

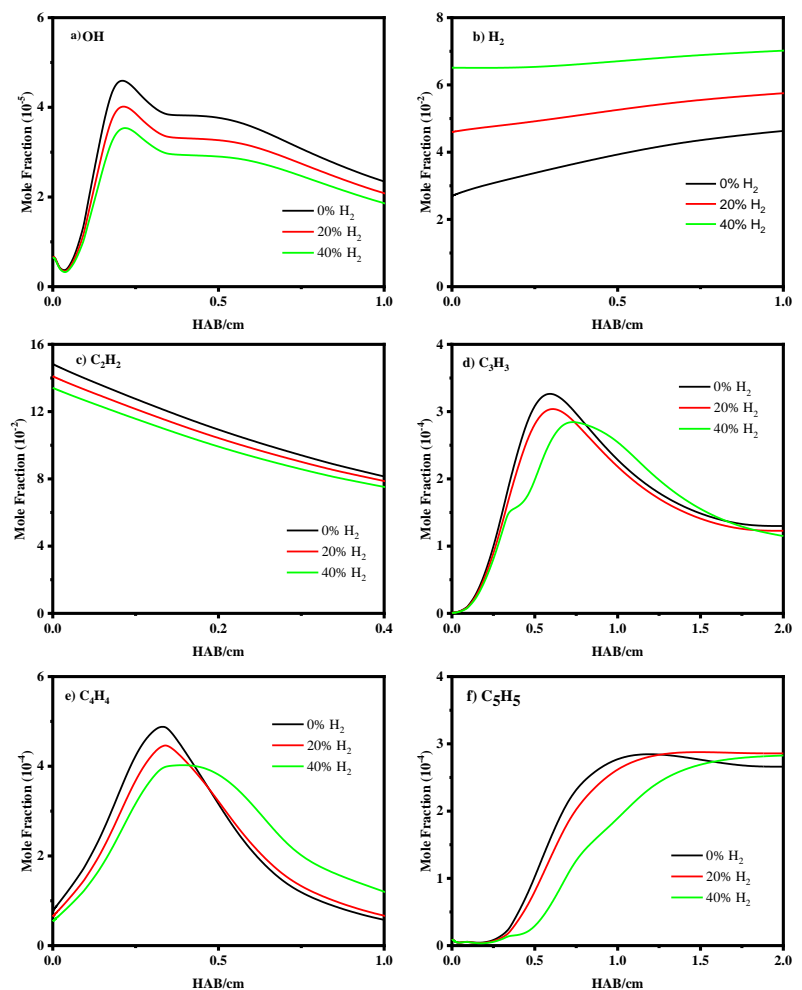

Fig. 9: Mole Fractions of a) $\mathrm{OH}$, b) $\mathrm{H}_{2}$, c) $\mathrm{C}_{2} \mathrm{H}_{2}$, d) $\mathrm{C}_{3} \mathrm{H}_{3}$, e) $\mathrm{C}_{4} \mathrm{H}_{4}$, f) $\mathrm{C}_{5} \mathrm{H}_{5}$ with $\mathrm{HAB}$.

Figure 10 (a) shows the relationship between mole fraction of $\mathrm{OH}$ (with $0 \%, 20 \%$ and 40\% $\mathrm{CO}$ additive) and $\mathrm{HAB}$. Figure 10 (a) showed that as the $\mathrm{CO}$ additive accelerates the forward reaction with $\mathrm{OH}$ and decreased the mole fraction of $\mathrm{OH}$. So, in result the mole fraction of $\mathrm{OH}$ becomes lower with $\mathrm{CO}$ addition. The following reactions take place:

$$
\mathrm{CO}+\mathrm{OH} \rightarrow \mathrm{CO}_{2}+\mathrm{H}
$$

Figure 10 (b) shows the relationship between mole fraction of $\mathrm{H}_{2}$ (with $0 \%, 20 \%$ and $40 \% \mathrm{CO}$ additive) and $\mathrm{HAB}$. It shows that the concentration of $\mathrm{H}_{2}$ gradually increases with $\mathrm{HAB}$. As the $\mathrm{CO}$ additive accelerates the forward reaction with $\mathrm{H}_{2}$. So, in result the mole fraction of $\mathrm{H}_{2}$ becomes lower with $\mathrm{CO}$ addition. In Figure 10 (c) the relationship between mole fraction of $\mathrm{C}_{2} \mathrm{H}_{2}$ (with $0 \%, 20 \%$ and $40 \% \mathrm{CO}$ additive) and $\mathrm{HAB}$ is shown. $\mathrm{CO}$ doesn't react with $\mathrm{C}_{2} \mathrm{H}_{2}$ but it will react with other species and affect the result. Hence, the dilution effect is observed upon adding $\mathrm{CO}$ to hydrocarbon fuel flame. So when $20 \%$ to $40 \% \mathrm{CO}$ was added to $\mathrm{C}_{2} \mathrm{H}_{2}$ /air flame, the mole fraction of $\mathrm{C}_{2} \mathrm{H}_{2}$ decreased. Figure 10 (d) depicts the relationship between mole fraction of $\mathrm{C}_{3} \mathrm{H}_{3}$ (with $0 \%, 20 \%$ and $40 \% \mathrm{CO}$ additive) and $\mathrm{HAB}$. Carbon monoxide caused dilution effect on hydrocarbon fuel flame. So when $20 \%$ to $40 \% \mathrm{CO}$ was added to $\mathrm{C}_{2} \mathrm{H}_{2}$ /air flame, the mole fraction of $\mathrm{C}_{3} \mathrm{H}_{3}$ decreased due to dilution. Figure 10 (e) illustrates the relationship between mole fraction of $\mathrm{C}_{4} \mathrm{H}_{4}$ (with $0 \%, 20 \%$ and $40 \% \mathrm{CO}$ additive) and $\mathrm{HAB}$. The addition of $\mathrm{CO}$ to hydrocarbon fuel flame yields several effects, including dilution, thermal, chemical effects, etc. So when $20 \%$ to $40 \% \mathrm{CO}$ was added to $\mathrm{C}_{2} \mathrm{H}_{2} /$ air flame, the mole fraction of $\mathrm{C}_{4} \mathrm{H}_{4}$ decreased. On the whole, the concentration of $\mathrm{C}_{4} \mathrm{H}_{4}$ first increased sharply and then decreased to a flat state with HAB. Figure 10 (4) illustrates the relationship between mole fraction of $\mathrm{C}_{5} \mathrm{H}_{5}$ (with $0 \%, 20 \%$ and $40 \% \mathrm{CO}$ additive) and $\mathrm{HAB}$. The dilution effect is because of the addition of $\mathrm{CO}$ to hydrocarbon fuel flame. So when $20 \%$ to $40 \% \mathrm{CO}$ was added to $\mathrm{C}_{2} \mathrm{H}_{2} /$ air flame, the value of mole fraction $\mathrm{C}_{5} \mathrm{H}_{5}$ slightly decreases due to dilution. 

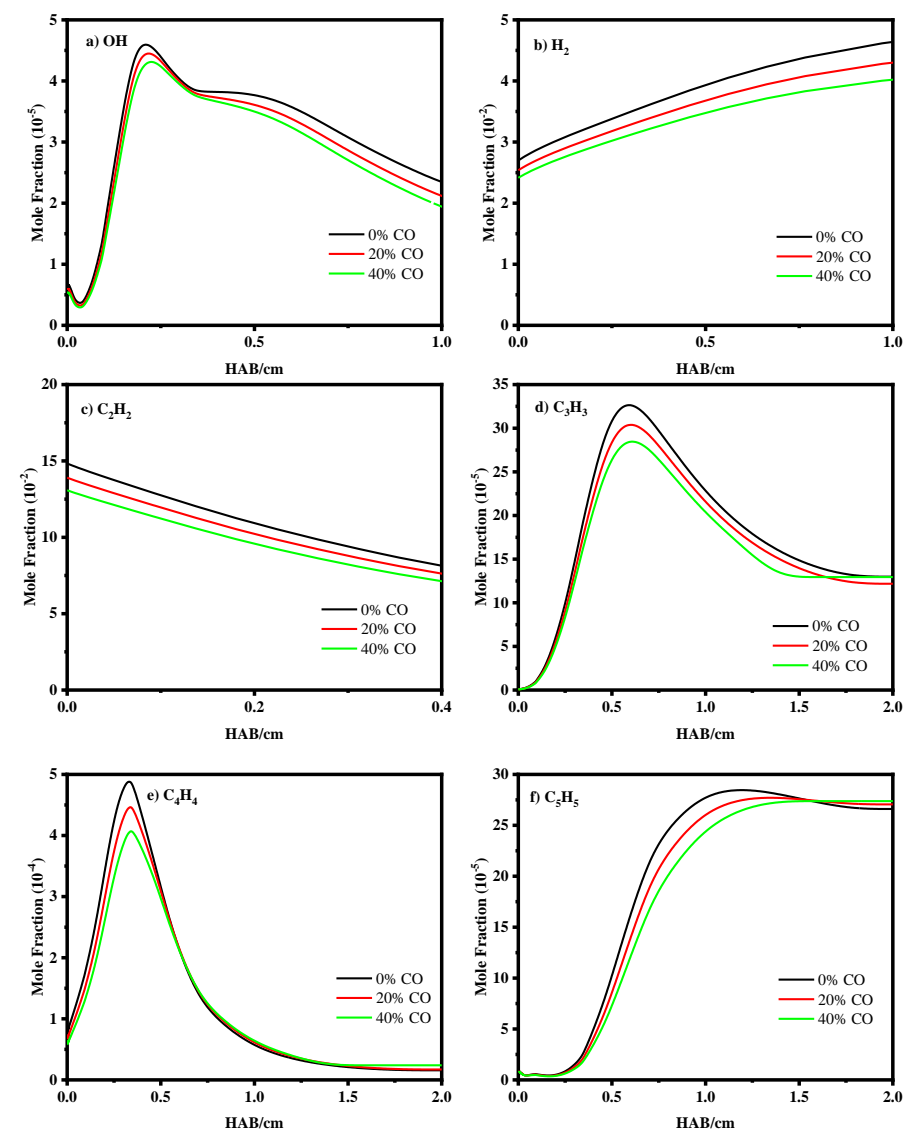

Fig. 10: Mole Fractions of a) $\mathrm{OH}$, b) $\mathrm{H}_{2}$, c) $\mathrm{C}_{2} \mathrm{H}_{2}$, d) $\mathrm{C}_{3} \mathrm{H}_{3}$, e) $\mathrm{C}_{4} \mathrm{H}_{4}$, f) $\mathrm{C}_{5} \mathrm{H}_{5}$ with $\mathrm{HAB}$.

Figure 11 (a) illustrates the relationship between mole fraction of $\mathrm{OH}$ (with $0 \%, 20 \%$ and $40 \% \mathrm{~N}_{2}$ additive) and $\mathrm{HAB}$. This is a forward reaction which consumes $\mathrm{OH}$ radical and due to which the mole fraction of $\mathrm{OH}$ started to decrease. Therefore, first the mole fraction of $\mathrm{OH}$ started to increase and after getting the maximum peak, the mole fraction of $\mathrm{OH}$ was started to decrease. It can clearly be seen that the results are very close to each other with two fluctuations (one is when reaction started and the other is after moving from maximum values). In other words, it is showing same trend with $0 \%, 20 \%$ and $40 \% \mathrm{~N}_{2}$ addition. Figure 11 (b) elucidates the relationship between mole fraction of $\mathrm{H}_{2}$ (with $0 \%, 20 \%$ and $40 \% \mathrm{~N}_{2}$ additive) and $\mathrm{HAB}$. When $\mathrm{N}_{2}$ is added in $\mathrm{C}_{2} \mathrm{H}_{2}$ /air flame, then it can be understanding that, mole fraction of $\mathrm{H}_{2}$ was maximum with $0 \% \mathrm{~N}_{2}$ and it was minimum with $40 \% \mathrm{~N}_{2}$. Furthermore, it was in between the minimum and maximum value, when $\mathrm{N}_{2}$ was $20 \%$. In other words, it is showing the decreasing trend with $0 \%, 20 \%$ and $40 \% \mathrm{~N}_{2}$ addition, because nitrogen is an inert gas but it effects the results due to dilution effect. Figure 11 (c) illustrates the relationship between mole fraction of $\mathrm{C}_{2} \mathrm{H}_{2}$ (with $0 \%, 20 \%$ and $40 \% \mathrm{~N}_{2}$ additive) and $\mathrm{HAB}$. It can clearly be seen that the results are very close to each other. In other words, it is showing same trend with $0 \%, 20 \%$ and $40 \% \mathrm{~N}_{2}$ addition and lowering the mole fraction of $\mathrm{C}_{2} \mathrm{H}_{2}$, and for all percentages addition of $\mathrm{N}_{2}$ decreased the mole fraction of $\mathrm{C}_{2} \mathrm{H}_{2}$ because nitrogen is an inert gas but it effects the results due to diffusion effect. Figure 11 (d) illustrates the relationship between mole fraction $\mathrm{C}_{3} \mathrm{H}_{3}$ (with $0 \%, 20 \%$ and $40 \% \mathrm{~N}_{2}$ additive) and $\mathrm{HAB}$. It can clearly be seen that the end results are very close to each other. In other words, it is showing same trend with $0 \%$ and $20 \% \mathrm{~N}_{2}$ but for $40 \% \mathrm{~N}_{2}$ addition it showed a fluctuation and lowering the mole fraction of $\mathrm{C}_{3} \mathrm{H}_{3}$. Figure 
11 (e) illustrates the relationship between mole fraction of $\mathrm{C}_{4} \mathrm{H}_{4}$ (with $0 \%, 20 \%$ and $40 \% \mathrm{~N}_{2}$ additive) and $\mathrm{HAB}$. It can clearly be seen that the end results are close to each other for $0 \%$ and $20 \%$ of $\mathrm{N}_{2}$ addition as compared to $40 \% \mathrm{~N}_{2}$ addition. In other words, it is showing same trend with $0 \%$ and $20 \% \mathrm{~N}_{2}$, but for $40 \% \mathrm{~N}_{2}$ addition it showed different and increased the mole fraction of $\mathrm{C}_{4} \mathrm{H}_{4}$ at high flame height. Figure 11 (f) is showing the relationship between mole fraction of $\mathrm{C}_{5} \mathrm{H}_{5}($ with $0 \%, 20 \%$ and $40 \% \mathrm{~N}_{2}$ additive) and $\mathrm{HAB}$. It is clearly mentioned that the mole fraction of $\mathrm{C}_{5} \mathrm{H}_{5}$ started to increase from $0.2 \mathrm{~cm}$, when the percentage of $\mathrm{N}_{2}$ was $0 \%$ and $20 \%$ it increased with same trend as seen in the figure. But for $40 \%$ addition of $\mathrm{N}_{2}$ case, it shows a bit different pathway. Before $\mathrm{HAB}=1.5 \mathrm{~cm}$, the concentration of $\mathrm{C}_{5} \mathrm{H}_{5}$ under $40 \% \mathrm{~N}_{2}$ addition was much lower than that under other conditions, but higher after that.
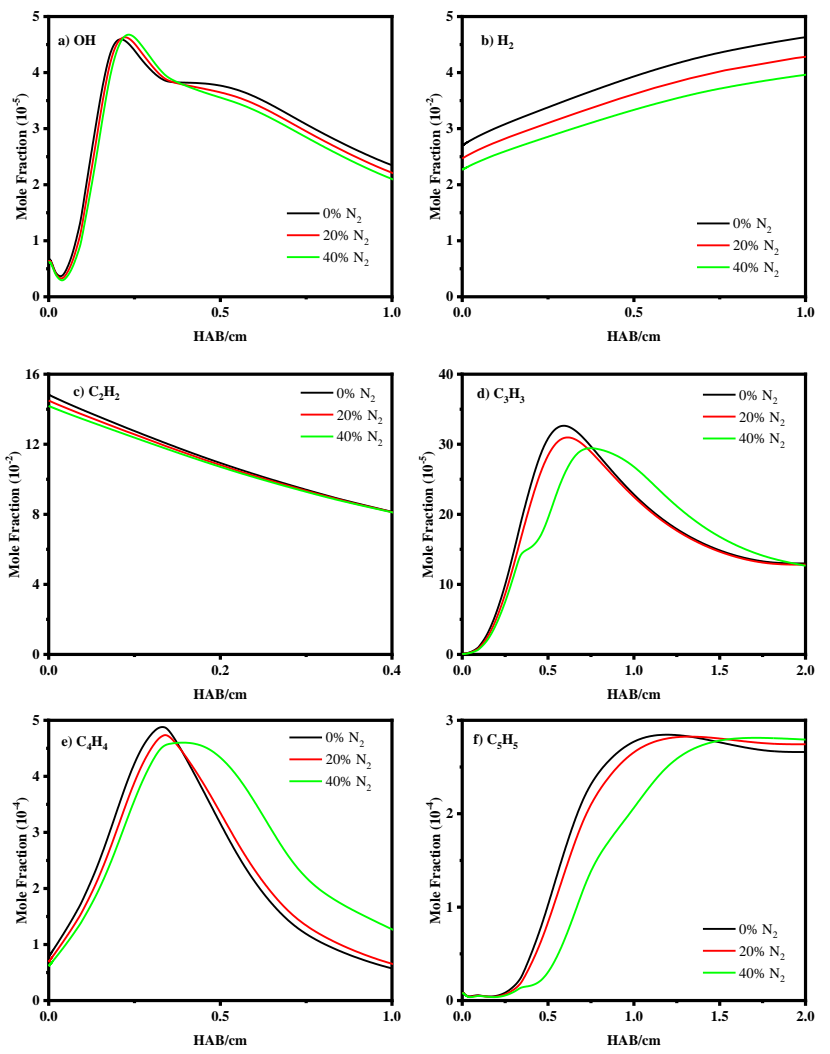

Fig. 11: Mole Fractions of a) $\mathrm{OH}$, b) $\mathrm{H}_{2}$, c) $\mathrm{C}_{2} \mathrm{H}_{2}$, d) $\mathrm{C}_{3} \mathrm{H}_{3}$, e) $\mathrm{C}_{4} \mathrm{H}_{4}$, f) $\mathrm{C}_{5} \mathrm{H}_{5}$ with $\mathrm{HAB}$.

\section{Soot Volume Fraction:}

To study the effects of $\mathrm{H}_{2}, \mathrm{CO}$ and $\mathrm{N}_{2}$ on formation of soot, $0 \%$ to $40 \% \mathrm{H}_{2}, \mathrm{CO}, \mathrm{N}_{2}$ were added in acetylene flame. In Figure 12 (a), (b), (c) showed that the soot formation reduced by the addition of $\mathrm{H}_{2}, \mathrm{CO}, \mathrm{N}_{2}$. 

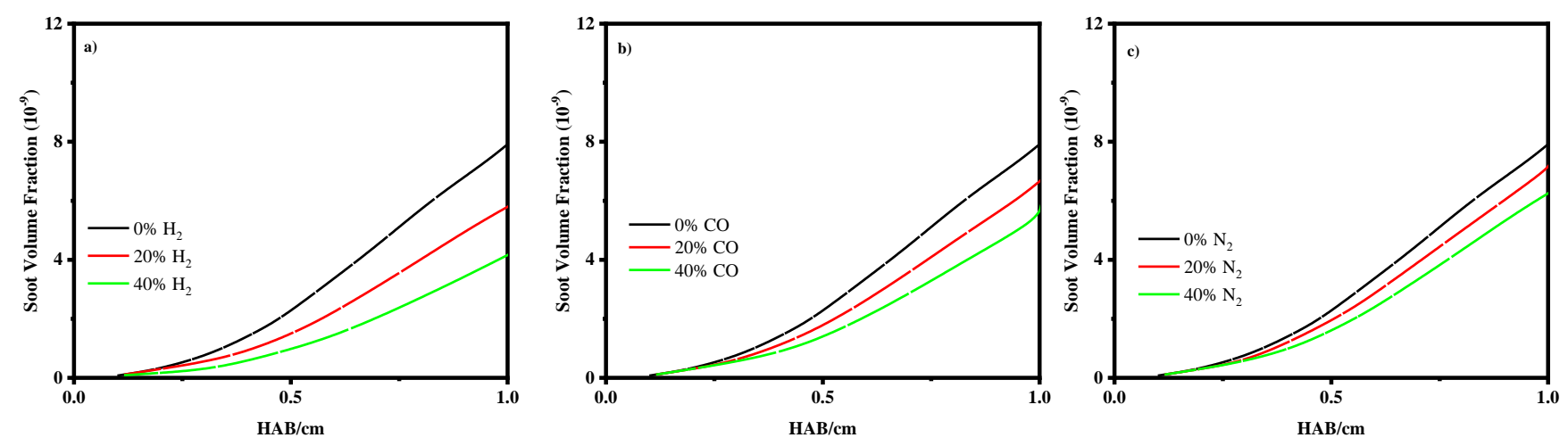

Fig. 12: Soot Volume Fraction with HAB.

\section{Conclusion}

For the study of PAHs and soot volume fraction, CHEMKIN software was used to analyse the behaviour of $\mathrm{H}_{2}, \mathrm{CO}$ and $\mathrm{N}_{2}$, addition on the PAHs and soot production in a premixed laminar $\mathrm{C}_{2} \mathrm{H}_{2}$ flame numerically. For the detail clarification of impact of additives on $\mathrm{PAH}$ formation and intermediate species like $\mathrm{OH}, \mathrm{H}_{2}$ and $\mathrm{C}_{2} \mathrm{H}_{2}, \mathrm{C}_{3} \mathrm{H}_{3}, \mathrm{C}_{4} \mathrm{H}_{4}, \mathrm{C}_{5} \mathrm{H}_{5}$ and soot volume fraction, some simulations were performed under different addition ratios $(0 \%, 20 \%$ and $40 \%)$ of $\mathrm{H}_{2}$, $\mathrm{CO}$ and $\mathrm{N}_{2}$. The ABF mechanism which includes $\mathrm{C}_{1}$ and $\mathrm{C}_{2}$ chemistry, benzene, PAH growth was used in the simulation to understand the particle inception and mole fractions of intermediate species. The main concluding contents are:

1.Carbon monoxide and Nitrogen showed diluents effects the PAH and reduced the PAH due to dilution. Hydrogen addition showed the chemical effect when added to fuel side and PAH were inhibited significantly as compared to carbon monoxide and nitrogen. By the addition of $\mathrm{H}_{2}$ a strong chemical effect on formation of $\mathrm{A} 4$ was observed and low mole fraction of A4 can be observed in flame of $\mathrm{C}_{2} \mathrm{H}_{2} / \mathrm{H}_{2} /$ air. Meanwhile, due to the abundance of $\mathrm{H}_{2}$ the aromatic radicals are restricted thus resulting in low production rate of larger PAHs. Hence among all these additives, to reduce PAH formation $\mathrm{H}_{2}$ can be a good additive.

2.At $0 \%$ addition of $\mathrm{H}_{2}, \mathrm{CO}$ and $\mathrm{N}_{2}$ in $\mathrm{C}_{2} \mathrm{H}_{2}$, the maximum temperature was $1742 \mathrm{~K}$. By increasing the concentration of $\mathrm{H}_{2}, \mathrm{CO}$ and $\mathrm{N}_{2}$ in $\mathrm{C}_{2} \mathrm{H}_{2}$ the temperature decreases and for $20 \%$ concentration of $\mathrm{H}_{2}, \mathrm{CO}$ and $\mathrm{N}_{2}$ it reduced to $1710 \mathrm{~K}$, $1719 \mathrm{~K}$ and $1725 \mathrm{~K}$ respectively. Similarly, for $40 \%$ concentration of $\mathrm{H}_{2}, \mathrm{CO}$ and $\mathrm{N}_{2}$, the temperature reduced to 1682 $\mathrm{K}, 1691 \mathrm{~K}$ and $1710 \mathrm{~K}$ respectively. This showed that these all additives have thermal effect. Hydrogen had a significant effect due to its chemical effect. $\mathrm{CO}$ is also having thermal effect but $\mathrm{N}_{2}$ showed fewer change in temperature due to its inert nature.

3. Carbon monoxide and Nitrogen showed diluents effects when added to fuel side and the mole concentrations of soot predecessor species for example $\mathrm{C}_{2} \mathrm{H}_{2}$ reduced due to dilution. The addition of $\mathrm{CO}$ reduces the concentration of $\mathrm{C}_{2} \mathrm{H}_{2}$. Hydrogen addition showed the chemical effect when added to fuel side and the mole concentrations of soot ancestor species like $\mathrm{C}_{2} \mathrm{H}_{2}$ were inhibited remarkably when compared to carbon monoxide and nitrogen. A strong chemical effect is observed in lowering the concentration of $\mathrm{C}_{2} \mathrm{H}_{2}$ in the $\mathrm{C}_{2} \mathrm{H}_{2} / \mathrm{H}_{2} /$ air flame by adding $\mathrm{H}_{2}$.

4.Carbon monoxide and Nitrogen showed diluents effects and soot volume fraction reduced due to dilution. Hydrogen addition showed the chemical effect when added to fuel side and the soot volume fraction were decreased significantly as compared to carbon monoxide and nitrogen. Hence among all these additives, $\mathrm{H}_{2}$ is an effective additive in lowering the formation of soot. 


\section{References}

[1] G. D. J. Guerrero Peña, Y. A. Hammid, and A. Raj, "On the characteristics and reactivity of soot particles from ethanolgasoline and 2, 5-dimethylfuran-gasoline blends," Fuel, vol. 222, pp. 42-55, 2018.

[2] Y. Liu, Y. Gao, and N. Yu, "Particulate matter, gaseous and particulate polycyclic aromatic hydrocarbons (PAHs) in an urban traffic tunnel of China: Emission from on-road vehicles and gas-particle partitioning," Chemosphere, vol. 134(5), pp. 52-59, 2015.

[3] H. Guo, K. A. Thomson, and G. J. Smallwood, "On the effect of carbon monoxide addition on soot formation in a laminar ethylene/air co-flow diffusion flame," Combustion and Flame, vol. 156(6), pp. 1135-1142, 2009.

[4] Ö. L. Gülder, "Influence of hydrogen addition to fuel on temperature field and soot formation in diffusion flames," Symposium on Combustion, 1996.

[5] A. Choudhary and S. Gollahalli, "Combustion characteristics of hydrogen-hydrocarbon hybrid fuels," Hydrogen Energy, vol. 25, pp. 451-462, 2000.

[6] R. Henríquez, R. Demarco, J. L. Consalvi, F. Liu, and A. Fuentes, "The oxygen index on soot production in propane diffusion flames," Combust. Sci. Technol, vol. 186 (4-6), pp. 504-517, 2014.

[7] A. D'Anna, "Detailed Kinetic Modeling of Particulate Formation in Rich Premixed Flames of Ethylene," Energy \& Fuels, vol. 22, pp. 1610-1619, 2008.

[8] M. Frenklach, "Method of moments with interpolative closure," Chem Eng Sci, vol. 57, pp. 2229-2239, 2002.

[9] J. Appel, H. Bockhorn, and M. Frenklach, "Kinetic modeling of soot formation with detailed chemistry and physics: laminar premixed flames of C2 hydrocarbons," Combust Flame, vol. 121, pp. 122-136, 2000.

[10] M. Frenklach, H. Wang, and H. Bockhorn, "Soot formation in combustion: mechanisms and models," Springer-Verlag, Heidelberg, pp. 165-192.

[11] R. J. Kee, F. M. Rupley, and J. A. Miller, "Chemkin-II: A fortran chemical kinetics package for the analysis of gasphase chemical kinetics," Sandia Rep, pp. SAND89-8009B, 1989.

[12] A. J, H. Bockhorn, and M. Wulkow, "A detailed numerical study of the variation of soot particle size distributions in laminar premixed flames," Chemosphere, vol. 42, pp. 635-645, 2001. 